\title{
SOBRE LENGUAJE, AUTORIDAD E HISTORIA INDÍGENA EN LOS COMENTARIOS REALES DE LOS INCAS DE MARGARITA ZAMORA
}

ABOUT LANGUAGE, AUTHORITY, AND INDIGENOUS HISTORY IN THE COMENTARIOS REALES DE LOS INCAS BY MARGARITA ZAMORA

\section{Nicolas Aizenberg \\ ORCID 0000-0003-2448-521X}

Universidad de Buenos Aires

Buenos Aires, Argentina

Reseña de ZAMORA, Margarita. Lenguaje, autoridad e historia en Los comentarios reales de los Incas. Trad. Juan Rodríguez Piñero; Vanina M. Teglia. Lima: Latinoamericana Editores, $2018^{1}$

La obra del Inca Garcilaso de la Vega, por su extensión y complejidad, ha dado lugar a múltiples debates para su exégesis. Al escritor se le ha considerado desde un cronista fiable hasta un fabulador, desde un humanista aculturado hasta "Un humanista inca" (David Brading), desde un escritor que buscaba la reconciliación entre etnias hasta alguien que fue leído por Tupac Amaru II como estímulo para su revolución, desde un hacedor de una utopía imposible hasta un promotor de un gobierno viable para el Perú. Margarita Zamora, en su libro Lenguaje, autoridad e historia indígena en los Comentarios de los Incas, de reciente publicación en español gracias a la traducción de Juan Rodríguez Pińero y Vanina M. Teglia, retoma y reelabora estas polémicas y profundiza algunos tópicos mencionados pero no profundizados por diversos estudios sobre la obra del gran cronista peruano.

1 Traducción al español de la edición de Cambridge: Language, Authority, and Indigenous History in the Comentarios reales de los Incas, Cambridge University Press, 1988 
En este libro, Zamora aborda los Comentarios reales desde la filología como construcción de autoridad y como llave de la historia. Para esto, la especialista realiza un exhaustivo racconto de la tradición humanista europea de la que se nutre el Inca Garcilaso, partiendo de figuras tales como Antonio de Nebrija, Lorenzo Valla, Erasmo y Fray Luis de León. En cuanto a Valla, en los escritos de la Antigüedad, se cifra el anhelo de la recuperación de un orden perdido, "en consecuencia, el mal uso del lenguaje o la traducción errónea constituían un ataque a ese orden" (ZAMORA, 2018, p. 44). En Erasmo, hay un deseo de volver a las fuentes cristianas a través de una purga y su correspondiente comentario. Y, por último, en Fray Luis, también se encuentra el proyecto de purificar dichas fuentes, pero teniendo en cuenta las potencialidades y limitaciones de la lengua en la que serán traducidas. A través de la contextualización, la autora demuestra los usos que hace Garcilaso de la tradición europea, es decir, cómo se nutre de ella para crear su propia autoridad: si con la conquista gana prestigio el punto de vista del testigo, el Inca deberá crear otros recursos de validación para su autoría teniendo en cuenta que su nacimiento es posterior y que el punto de vista de los cronistas suele ser el del conquistador. Si el cronista insiste en que los españoles todo lo corrompen, y que los infortunios del virreinato se debían a una falta de comprensión lingüística, entonces los europeos carecerían de las competencias necesarias para una cabal comprensión de los nativos, sus costumbres y su pasado. Así, el cronista parte de la idea de que el trauma de la conquista no fue fruto de los deseos de posesión y dominio por parte de los españoles -como podría argumentar un Fray Bartolomé de Las Casassino de la falta de comprensión entre lenguas y culturas tan diversas entre sí. Pero si el problema del primer encuentro entre los representantes de España y los del Incario fue de corte lingüístico, esto le permite al autor posicionarse mejor que un testigo: con Los comentarios reales pasamos del paradigma del punto de vista al paradigma filológico con el que se obtendría un acceso más verdadero, tanto a los sucesos precolombinos como a los de la conquista, gracias al conocimiento de las lenguas de los sectores en pugna y no gracias a una experiencia de primera mano. A su vez, a través de la comparación entre Las Casas y el Inca, Zamora demuestra que, al correr el eje de la crítica a los españoles (de ambiciosos a ignorantes), la crítica de Garcilaso es más sutil, al mismo tiempo que más vehemente: la cultura letrada y la cultura del libro poseen un límite epistemológico. 
La autora recuerda la concepción de Nebrija: la filología como forma de recuperar el origen perdido. Con este método, las palabras recobrarían un significado esencial y arrojarían luz sobre el pasado de una cultura otra o propia, actual o perdida. Este clima intelectual de época avala que el Inca Garcilaso asegure que la confusión lingüística de los españoles conlleva errores múltiples. De esta manera, la filología es una llave al pasado: a través de un estudio de la lengua, se pueden establecer períodos históricos. Esto va a sostener Garcilaso para defender al gobierno incaico de acusaciones tales como tiranías o sacrificios humanos ante sus detractores. Al confundir las palabras quechuas, el europeo mezcló y, según el Inca Garcilaso, malinterpretó la teología incaica. De esta manera, confundieron las dos etapas precolombinas, la pre-incaica y la incaica (ZAMORA, 2018, p. 88). Esta torre de Babel llevó a que los españoles confundieran a los Incas y los interpretaran como hacedores de los actos barbáricos antes señalados. El autor de los Los comentarios sostendría que los españoles no serían buenos conocedores de la religión e historia incaicas sino, más bien, que habrían carecido de los conocimientos para comprenderlas. Las consecuencias de esta afirmación de Garcilaso se vuelven preocupantes para la España católica e imperialista: al no poder conocer bien a otras culturas, la labor evangélica se dificulta, con lo que se corre el riesgo de que los nativos vuelvan a los cultos pre-incaicos, según demuestra Zamora.

\section{Providencia y mundo andino}

¿Cuáles serían los riesgos de una vuelta a las creencias pre-incaicas, además de los sacrificios humanos o de la antropofagia? Al establecer su rol como "traductor" entre culturas, Garcilaso establece una cronología que comienza con aquellos pueblos barbáricos, seguida por la expansión de la civilización cusqueña como foco que irradia un proto-cristianismo y, por último, la venida del cristianismo propiamente dicho. La diferenciación entre etapas en el período precolombino ya había sido llevada a cabo por otros cronistas. La sagacidad garciliana se funda en conectar esas etapas con la actual, la cristiana. Estas tres fases se encuentran unidas gracias a la providencia divina, es decir, hay una intervención divina para arrancar a los indígenas de su período desgraciado hacia uno civilizado. De esta forma, el período incaico no es algo anecdótico sino crucial para la pacificación de los indígenas y su preparación para el evangelio. Ahora bien, los españoles, al confundir ambas etapas, persiguen las costumbres incaicas y terminan erosionando el eslabón de esa cadena que conectaría al cristianismo. Como indica Zamora, "para Garcilaso la idea de una teología monoteísta inca está unida a su presentación del Tahuantinsuyu como praeparatio evangelica, lo 
que le garantiza, a la civilización inca, un lugar de privilegio en la historia cristiana" (ZAMORA, 2018, p. 37). La autora explica que la presentación de una religión amerindia proto-cristiana o proto-monoteísta es una estrategia de Garcilaso para presentar, al Cuzco y a sus gobernantes, como piezas importantes de la historia universal y como propagadores del monoteísmo y no como idólatras y tiranos. De esta manera, lo que han perdido los españoles es la posibilidad de cristianizar por métodos pacíficos a los indígenas, porque no han comprendido el rol del Cuzco como foco civilizador ni que Pachacámac, en realidad, no haya sido el diablo sino una intuición racional del verdadero Dios cristiano. Al perseguir el culto inca en vez de guiarlo hacia el cristiano, los indígenas se refugian en viejos dioses. Esto indica dos cosas: un atraso para los planes evangelizadores (los cristianos sabotean su propia misión), pero, además, según Zamora demuestra de manera lúcida, el hecho de que Garcilaso da a entender que los Incas civilizaban sin perseguir otros cultos, es decir, la autora evidencia una de las tantas críticas veladas hechas por el cronista.

\section{Utopía pero con topos}

Uno de los puntos más fuertes del libro Lenguaje, autoridad e historia indigena en los Comentarios de los Incas radica en la profundización del concepto de utopía en el Inca Garcilaso, mencionado por varios estudios pero no profundizado. Para comprender los alcances de este concepto, Zamora desarrollará la propuesta de Tomás Moro y su Utopía para luego mostrar su articulación en los Comentarios reales. Como ella señala, Utopia es un "modelo político de una civilización americana imaginaria” (ZAMORA, 2018, p. 149). De esta forma, el gobierno perfecto que diseñó el inglés sirve como modelo para el Inca. La diferencia está en que, para el primero, era una proyección mientras que, para el segundo, algo real y concreto, anclado en la historia. Pero el uso que hará el cronista peruano irá más allá. Según Zamora, el Inca realizó una traducción, pero no en el sentido que habitualmente se le da. Ella citará al lingüista y crítico literario Roman Jakobson, quien propone una traducción intersemiótica, es decir, un concepto que sea común a ambas culturas (la utopía, en este caso), a fin de poder explicar a los europeos lo que fue el Tahuantinsuyu (ZAMORA, 2018, p. 154-5). De esta forma, Zamora no se contenta con señalar que estamos ante un discurso utópico sino que explica cómo opera este concepto renacentista en la crónica y con qué fines es utilizado.

Para concluir, la traducción de Lenguaje, autoridad e historia indigena en los Comentarios de los Incas, realizada por Juan Rodríguez Piñero y Vanina Teglia, acerca, al mundo hispanohablante, un libro necesario para seguir pensando la obra garciliana y para cuestionar y profundizar algunas perspectivas trabajadas por otros críticos, centrándose en las estrategias discursivas que 
realizara Garcilaso para construir su autoridad ante los cronistas con los que está polemizando. Un libro que reabre nuevas discusiones sobre el cronista mestizo en cuanto a los usos de las tradiciones humanista y cristiana.

\section{Referencias}

LA VEGA, Garcilaso de. Comentarios Reales. Lima: Editorial Mercurio, 1970.

ZAMORA, Margarita. Lenguaje, autoridad e historia en Los comentarios reales de los Incas. Trad. Juan Rodríguez Piñero; Vanina M. Teglia. Lima: Latinoamericana Editores, 2018.

ZAMORA, Margarita. Language, Authority, and Indigenous History in the Comentarios reales de los Incas. Cambridge: Cambridge University Press, 1988.

Nicolás Aizenberg. Estudiante de la carrera de Letras de la Universidad de Buenos Aires y adscripto a la cátedra Literatura latinoamericana I (cátedra Colombi) de la misma universidad con un proyecto de investigación sobre "El Inca Garcilaso de la Vega y su visión pesimista del Perú colonial", dirigido por Vanina Teglia. Ha participado como expositor de varios congresos de literatura colonial.

E-mail: nicolasaizen@gmail.com 